\title{
Diffusion Bonding of a Superplastic Inconel 718SPF Superalloy by Electroless Nickel Plating
}

\author{
M.S. Yeh, C.B. Chang, and T.H. Chuang
}

(Submitted 1 March 1999; in revised form 19 May 1999)

\begin{abstract}
Although intimate contact can be obtained for diffusion bonding of a superplastic Inconel 718SPF superalloy under a low pressure of $7 \mathrm{MPa}$, the precipitates formed at the interface retarded achievement of a sound joint. The shear strength was only $41.5 \mathrm{MPa}$ for an overlap length of $12 T(T=1.3 \mathrm{~mm}$, sheet thickness). The diffusion bondability of this Inconel 718SPF superalloy was enhanced by electroless nickel plating. In this situation, the bonding shear strength increased to $70.4 \mathrm{MPa}$ for the same overlap length of $12 \mathrm{~T}$ under the same bonding condition, regardless of the roughness of the surface to be bonded. Upon decreasing the overlap length from 12 to $6 T$, the bonding strength remained constant.
\end{abstract}

\begin{tabular}{|ll|}
\hline Keywords & $\begin{array}{l}\text { diffusion bonding, electroless nickel plating, Inconel } \\
718 \mathrm{SPF} \text { superalloy }\end{array}$ \\
\hline
\end{tabular}

\section{Introduction}

Nickel-base superalloys have been widely used in the automobile, aerospace, and nuclear industries. The joining process for manufacturing nickel-base superalloy complex components, such as gas turbine engines, is very important. However, nickelbase superalloys are more difficult to join using the diffusion bonding process, especially when the nickel-base superalloy contains aluminum and titanium, which will significantly affect the diffusion bonding characteristics of this alloy. ${ }^{[1]}$ These alloying elements form tenacious surface oxides that retard the bonding process. Several methods have been developed for producing satisfactory solid-state diffusion bonds in nickel-base superalloys. Moore and Glasgow ${ }^{[2]}$ found that an oxide-dispersionstrengthened nickel-base superalloy could be successfully bonded at $1000^{\circ} \mathrm{C}$ at $27.6 \mathrm{MPa}$ for $1.25 \mathrm{~h}$. A two-step welding technique $\left(705^{\circ} \mathrm{C}\right.$ at $207 \mathrm{MPa}$ for $1 \mathrm{~h}, 1190^{\circ} \mathrm{C}$ at $15 \mathrm{MPa}$ for $2 \mathrm{~h}$ ) was conducted by Holko and Moore ${ }^{[3]}$ to enhance the TD$\mathrm{NiCr}\left(\mathrm{Ni}-20 \mathrm{Cr}\right.$ matrix, which contains a fine dispersion of $\mathrm{ThO}_{2}$ particles) sheet joint quality. Furthermore, diffusion bonding can be promoted by an intermediate coating on the bonding surfaces as a joining aid. ${ }^{[4-7]}$ The roles of the coating are to promote contact between the two surfaces and to minimize undesirable intermetallic components. For example, Udimet 700 superalloy (Special Metals Corp., New Hartford, NY) was bonded using a thin electroplated nickel-cobalt interlayer on the mating surfaces at $2140^{\circ} \mathrm{F}$ at $1 \mathrm{ksi}$ for $3 \mathrm{~h} \cdot{ }^{[7]}$

A superplastic alloy possesses lower flow stress, which is beneficial to the formation of an intimate contact interface during the diffusion bonding process. Furthermore, the very fine grain size of a superplastic alloy provides a large number of grain bound-

M.S. Yeh, Department of Mechanical Engineering, Chung-Hua University, Hsin-Chu, Taiwan, Republic of China; C.B. Chang, Materials Research and Development Center, Chung-Shan Institute of Science and Technology, Lungtan, Taoyuan, Taiwan, Republic of China; and T.H. Chuang, Institute of Materials Science and Engineering, National Taiwan University, Taipei, Taiwan, Republic of China. aries, which is advantageous for the diffusion of elements. Both effects imply that a superplastic alloy possesses better diffusion bondability than a conventional alloy with the same composition. The Inconel 718SPF superalloy (INCO Alloys International, Inc., Huntington, WV) with a grain size of $107 \mu \mathrm{m}$ or finer has been commercially produced to possess superplasticity. Its tensile elongation has been shown to reach approximately $194.0 \%$ with an initial strain rate of $1.3 \times 10^{-3} / \mathrm{s}$ at a temperature of $954^{\circ} \mathrm{C} .{ }^{[8]}$ It was expected that such a superplastic superalloy could be diffusion bonded more effectively than a conventional superalloy, which has been considered to be a difficult alloy for diffusion bonding. The present study showed that, although an intimate contact interface was obtained for diffusion bonding of a superplastic Inconel 718 superalloy as expected, the bonding strength was very low. Further enhancement of the bonding effect by means of electroless nickel plating is proposed.

\section{Experimental Procedure}

An Inconel 718SPF superalloy sheet with the chemical composition shown in Table 1 was used in this study. Strips of this alloy with dimensions of 34 by 15 by $1.3 \mathrm{~mm}$ were cut from the sheet material. The surfaces were prepared for bonding in two different ways. Some specimen bonding surfaces were prepared by polishing with $0.3-\mu \mathrm{m}$ alumina power. Other specimen bonding surfaces were prepared by grinding with 600 -grit $\mathrm{SiC}$ paper, followed by electroless nickel plating. The arithmetical averages of roughness, $R_{a}$, were measured using a surface roughness meter. Figure 1 shows a schematic of the electroless nickel plating process used in this study. Before bonding, these strips were cleaned by rinsing in distilled water, followed by ultrasonic cleaning in acetone for $5 \mathrm{~min}$.

Electroless nickel plating is an autocatalytic reaction process. The nickel ions $\left(\mathrm{Ni}^{+3}\right)$, which exist in a nickel electroless bath, react with hypophosphorus ions $\left(\mathrm{H}_{2} \mathrm{PO}^{-}\right)$to form nickel atoms. Meanwhile, the hypophosphorus ions react with nascent hydrogen to form phosphorus atoms. These atoms deposit on the surface of the Inconel 718SPF superalloy to form an electroless nickel-phosphorus alloy. The nominal reaction is

$\mathrm{N}_{\mathrm{i}}^{+2}+\mathrm{H}_{2} \mathrm{PO}_{2}^{-} \rightarrow \mathrm{N}_{\mathrm{i}}+2 \mathrm{H}^{+}+\mathrm{H}_{2} \mathrm{PO}_{3}^{-}$

(Eq 1) 


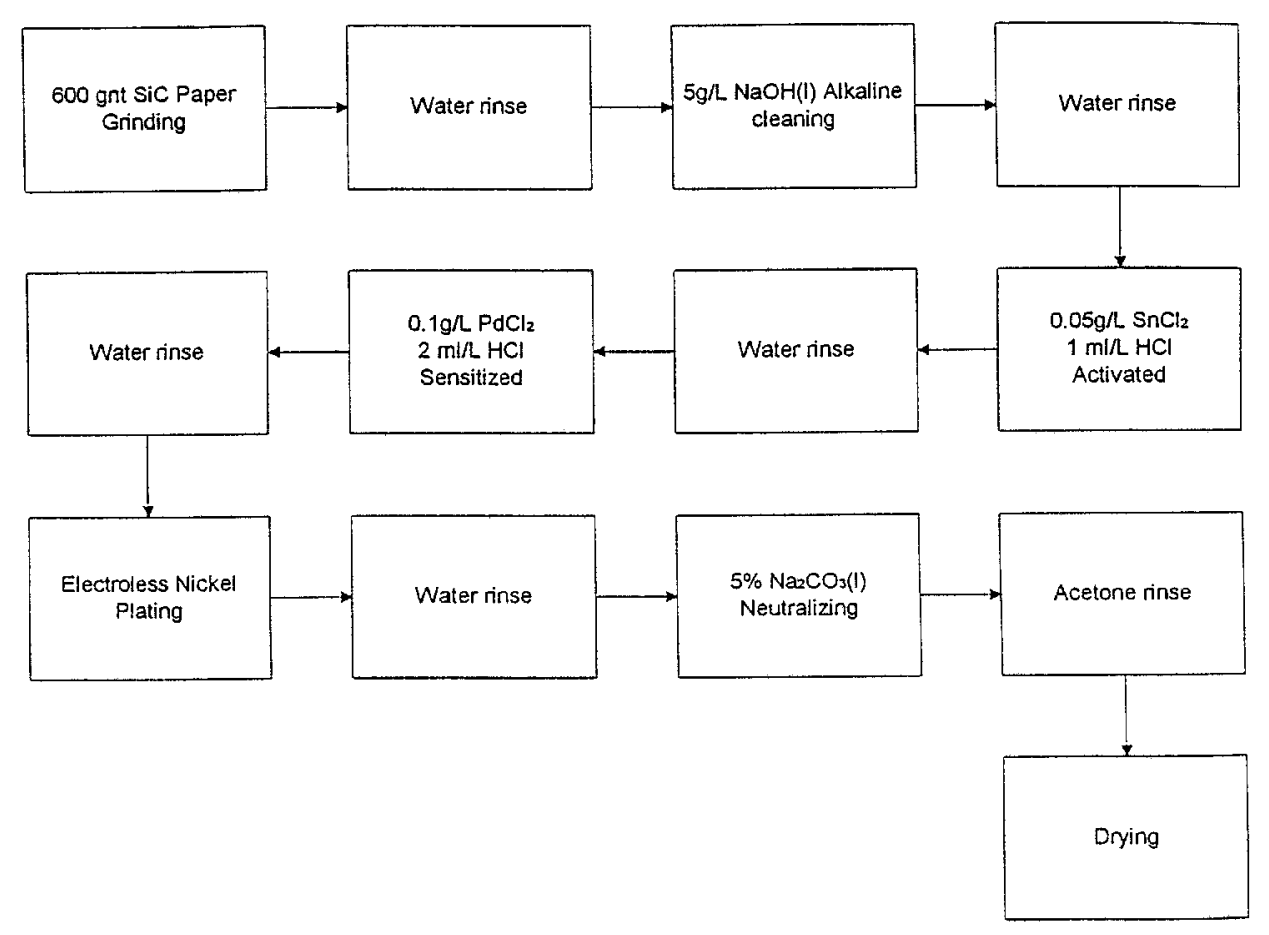

Fig. 1 Typical electroless nickel plating process

Table 1 The chemical composition of Inconel 718SPF superalloy

\begin{tabular}{lc}
\hline Element & Composition, \% \\
\hline $\mathrm{C}$ & 0.03 \\
$\mathrm{Mn}$ & 0.08 \\
$\mathrm{Fe}$ & 17.9 \\
$\mathrm{Si}$ & 0.11 \\
$\mathrm{Cu}$ & 0.09 \\
$\mathrm{Ni}$ & 53.85 \\
$\mathrm{Cr}$ & 18.26 \\
$\mathrm{Al}$ & 0.53 \\
$\mathrm{Ti}$ & 1.06 \\
$\mathrm{Co}$ & 0.15 \\
$\mathrm{Mo}$ & 3.01 \\
$\mathrm{P}$ & 0.011 \\
$\mathrm{~B}$ & 0.002 \\
$\mathrm{~S}$ & 0.001 \\
$\mathrm{Nb}+\mathrm{Ta}$ & 4.92 \\
\hline
\end{tabular}

Two Inconel 718SPF strips were arranged with an overlap of $12 T$ ( $T=1.3 \mathrm{~mm}$, sheet thickness). For the electroless nickelplated specimens, the effects of various overlap lengths from 3 to $12 T$ were also studied. The tests were then carried out in a hot press under a vacuum of $10^{-4}$ torr at $1000^{\circ} \mathrm{C}$ for $30 \mathrm{~min}$ with an applied pressure of $7 \mathrm{MPa}$. After bonding, these specimens were machined to the dimensions shown in Fig. 2, using a wire-cut electric discharge machine to determine the shear strength of the bonded specimens. These tests were carried out in air at room temperature at a crosshead speed of $0.5 \mathrm{~mm} / \mathrm{min}$. The shear strength, $\tau$, was calculated by the equation

$$
\tau=\frac{P}{A W}
$$
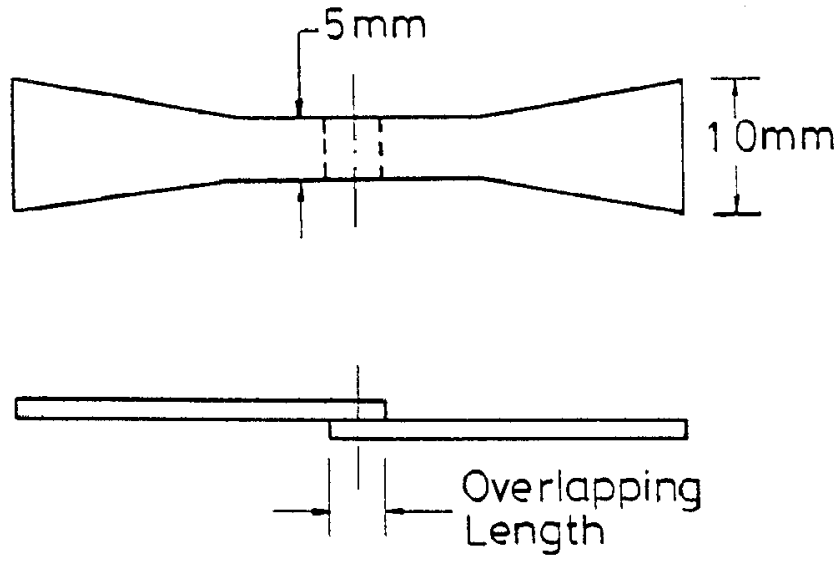

Fig. 2 The dimensions for a single lap shear test specimen

where $P$ is the breaking load, $A$ is the overlap length, and $W$ is the sample width. The shear strength was determined as the average taken from three bonded specimens. Microstructures and fracture surfaces were observed using a scanning electron microscope. The compositions were analyzed using electron probe microanalysis.

\section{Results and Discussion}

The diffusion bonding of Inconel 718SPF superalloy with a polished faying surface $\left(R_{a}=0.10 \mu \mathrm{m}\right)$ was first conducted at $1000{ }^{\circ} \mathrm{C}$ for $30 \mathrm{~min}$ under an applied pressure of $7 \mathrm{MPa}$. No 
voids were found at the bonding interface as observed by optical microscopy. This was due to the fact that the superplastic materials could be deformed under lower flow stress in the superplastic deformation temperature of this alloy, which resulted in an increase of the contact area. Also, the very fine grain size implied a large number of grain boundaries, which are beneficial diffusion paths. However, many precipitates were observed along the bonding interface, as shown in the scanning electron micrograph (Fig. 3). These precipitates retarded interface migration, which is necessary for a sound joint to be achieved. The shear strength was only 41.5 MPa in this case. All the specimens failed at the bonding interface after tensile shear tests. A shear fracture surface was common, as shown in Fig. 4. In order to avoid the precipitate formation and improve the bonding capability, electroless nickel plating on the bonding surface of the Inconel 718SPF superalloy was employed.

An acid nickel electroless bath (Niklad 796, Allied-Kelite Division, the Witoc Chemical Corporation, Melrose Park, IL) was used in this study. Nickel sulfate $\left(\mathrm{NiSO}_{4} \cdot 6 \mathrm{H}_{2} \mathrm{O}\right)$ was the main source of nickel ions, and sodium hypophosphate $\left(\mathrm{Na}_{2} \mathrm{H}_{2}\right.$ $\mathrm{PO}_{2} \cdot \mathrm{H}_{2} \mathrm{O}$ ) was the reducing agent. The $\mathrm{pH}$ value of the bath was 4.8. An Inconel 718SPF superalloy with its surface ground using 600-grit $\mathrm{SiC}$ paper was immersed in this solution at a temperature of $92 \pm 3{ }^{\circ} \mathrm{C}$ for $15 \mathrm{~min}$. The thickness of the electroless nickel was about $12 \mu \mathrm{m}$, and the arithmetical average of roughness was $0.11 \mu \mathrm{m}$. Its melting characteristics were determined by differential thermal analysis, and Figure 5 shows the liquidus and solidus. The chemical composition of the electroless nickel, analyzed using energy dispersive x-ray spectrometry (EDX), was Ni-5.95 wt.\%P.

Figure 6(a) shows the microstructure of diffusion bonding of Inconel 718SPF superalloy with electroless nickel. No voids were observed at the bonding interface under the bonding conditions (1000 ${ }^{\circ} \mathrm{C}$ at $7 \mathrm{MPa}$ for $30 \mathrm{~min}$ ). Electron probe microanalysis showed that the phosphorus atoms accumulated at the electroless nickel/base metal interface. The appearance of chromium in the joint was evidence of diffusion out of chromium from the solid base metal in the diffusion bonding process (Fig. 6(a)). The bonded joint was occupied by nickel solid solution, which contained higher concentrations of chromium and iron (Fig. 6(b)) than the original electroless nickel (Fig. 6(c)). Because the diffusion bonding process was conducted at $1000^{\circ} \mathrm{C}$, which was higher than the liquidus of electroless nickel $\left(901.4^{\circ} \mathrm{C}\right.$, Fig. 5), the latter melted during the heating process. There were two beneficial effects of Inconel 718SPF superalloy diffusion bonding in this case. First, scratches on the mating surface were filled by molten electroless nickel, promoting diffusion of atoms in the diffusion bonding process. The alloys were satisfactorily bonded with a rather crude surface preparation. Second, the molten electroless nickel reacted with the base metal and destroyed the tenacious surface oxides, which resulted in a decrease of the diffusion barrier layer. Meanwhile, phosphorus from the molten electroless nickel diffused into the base metal, and isothermal solidification of the nickel solid solution occurred in the joint. The phosphorus had very little solubility in the nickel solid solution, so the phosphorus was expelled and accumulated at the electroless nickel/base metal interface.

Because the shear stress is highest toward the ends of the joint when a single lap specimen has an overlap length beyond

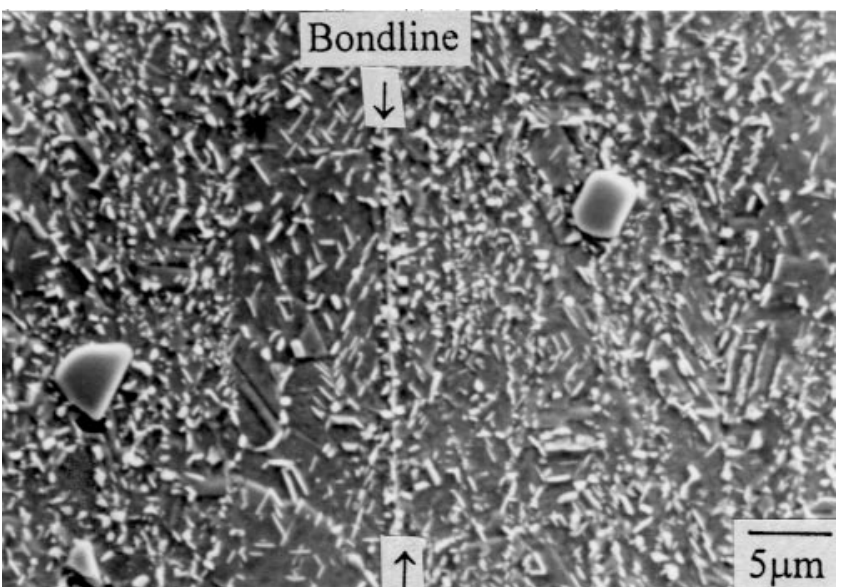

Fig. 3 Microstructure of diffusion bonding with a polished faying surface under a vacuum of $10^{-4}$ torr at $1000{ }^{\circ} \mathrm{C}$ for $7 \mathrm{MPa}$ for $30 \mathrm{~min}$



Fig. 4 Fractographs of diffusion bonds with a polished faying surface at $1000{ }^{\circ} \mathrm{C}$ at $7 \mathrm{MPa}$ for $30 \mathrm{~min}$ (overlapping length $6 \mathrm{~T}$ )

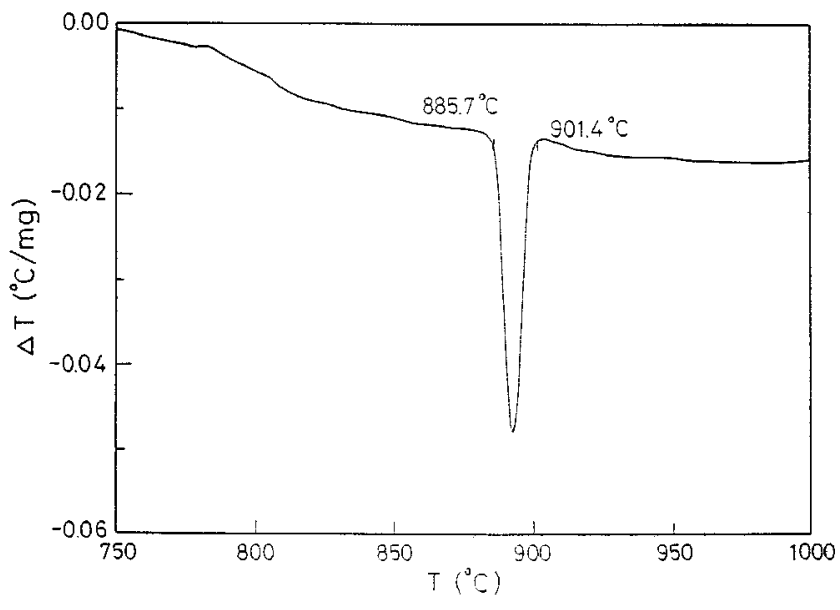

Fig. 5 Thermograms of electroless nickel plating 

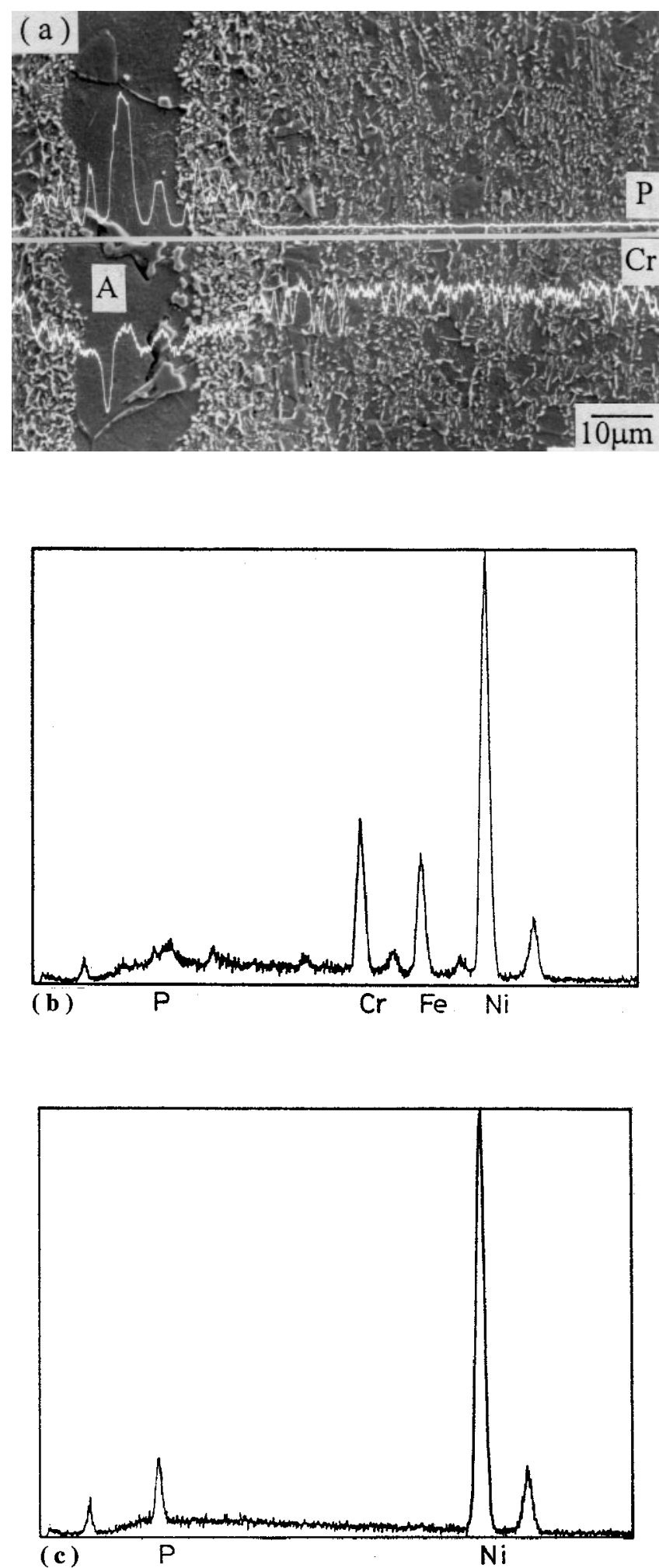

Fig. 6 (a) Distribution curves of the intensity of various elements analyzed across the bonding interface of Inconel 718SPF superalloy with electroless nickel under a vacuum of $10^{-4}$ torr at $1000{ }^{\circ} \mathrm{C}$ at $7 \mathrm{MPa}$ for $30 \mathrm{~min}$ by electron probe microanalysis. (b) The energy dispersive $\mathrm{x}$-ray spectrum for the nickel solid solution (position A in (a). (c) The energy dispersive $\mathrm{x}$-ray spectrometry (EDX) for electroless nickel a certain value, ${ }^{[9]}$ the central portion of a long lap joint carries little or no load. In this case, the bonding strength does not improve. This is the reason for the shear strength decrease with an increasing overlap length, and the result was also confirmed in this study. Furthermore, Donford and Partridge ${ }^{[10]}$ found that the failure mode of a single lap specimen changed from shear failure to peel failure with an increasing overlap length.

In this study, the shear strength increased to $70.4 \mathrm{MPa}$ with electroless nickel plating for an overlap length of $12 T$ under $1000{ }^{\circ} \mathrm{C}$ at $7 \mathrm{MPa}$ for $30 \mathrm{~min}$ bonding conditions. Upon decreasing the overlap length from 12 to $6 \mathrm{~T}$, the bonding strength remained constant (Fig. 7). However, the bonding strength increased to 107.2 MPa for the overlap length of $3 \mathrm{~T}$. Figure 8 shows the brittle fracture surfaces of the diffusion bonds for Inconel 718SPF superalloy with electroless nickel plating. All the

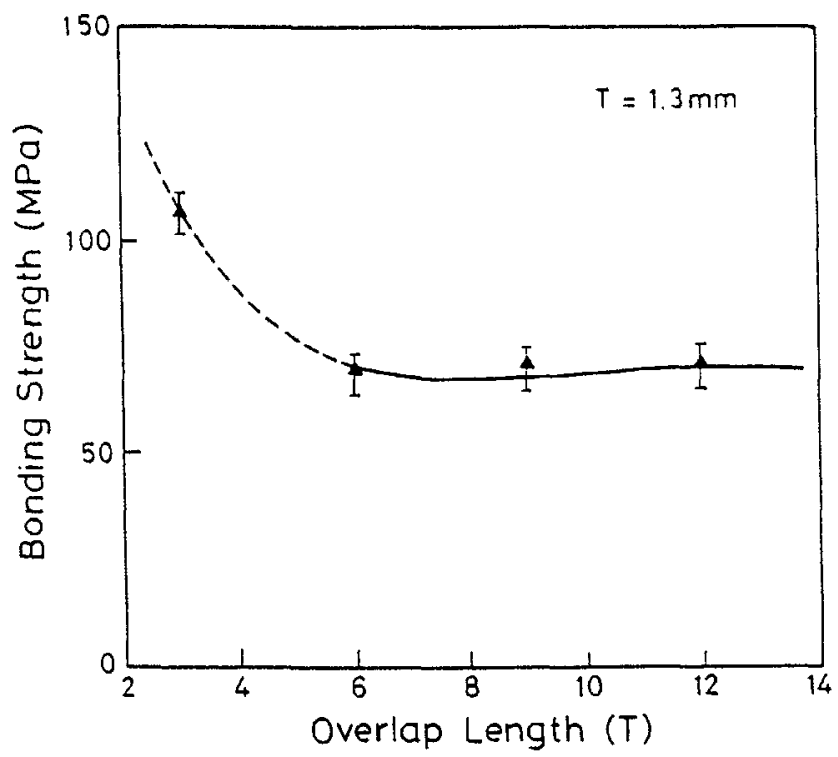

Fig. 7 Bonding strength of Inconel 718SPF superalloy with electroless nickel plating (bonding condition: $1000{ }^{\circ} \mathrm{C}$ at $7 \mathrm{MPa}$ for $30 \mathrm{~min}$ )

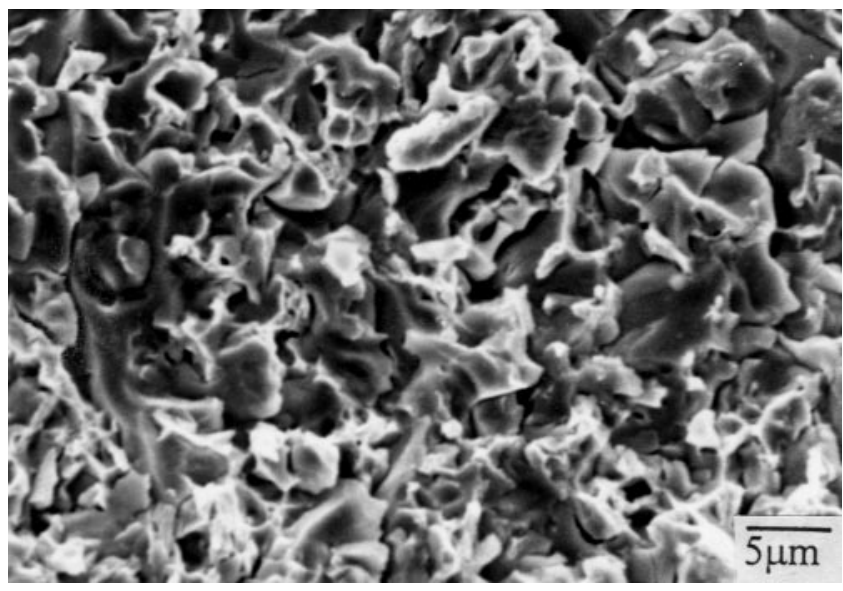

Fig. 8 Fractographs of diffusion bonds with electroless nickel at $1000^{\circ} \mathrm{C}$ at $7 \mathrm{MPa}$ for $30 \mathrm{~min}$ (overlapping length, $6 \mathrm{~T}$ ) 
bonds failed along the electroless nickel/base metal interface in tensile shear tests.

\section{Conclusions}

The following conclusions can be drawn.

Since the precipitates formed along the bonding interface, the Inconel 718SPF superalloy could not be satisfactorily bonded under $7 \mathrm{MPa}$ at $1000{ }^{\circ} \mathrm{C}$ for 30 min even with a polished bonding surface. The shear strength was only $41.5 \mathrm{MPa}$ for an overlap length of $12 T$. The bonding effect was enhanced by electroless nickel plating. The bonding shear strength increased to $70.4 \mathrm{MPa}$ for an overlap length of $12 \mathrm{~T}$ under $1000{ }^{\circ} \mathrm{C}$ at $7 \mathrm{MPa}$ for 30 -min bonding conditions. Upon decreasing the overlap length from 12 to $6 T$, the bonding strength remained constant. In this diffusion bonding process, an Inconel 718SPF superalloy can be satisfactorily bonded with a rather crude surface preparation.

\section{References}

1. W.T. Kaarlela and W.S. Margolis: Weld. J., 1967, vol. 46 (6), pp. $283 \mathrm{~s}-288 \mathrm{~s}$

2. T.J. Moore and T.K. Glasgow: Weld. J., 1985, vol. 64 (8), pp. 219s226s.

3. K.H. Holko and T.J. Moore: Weld. J., 1972, vol. 51 (2), pp. 81s-89s.

4. M. O'Brine, C.R. Rich, and D.L. Olson: Weld J., 1976, vol. 55 (1), pp. 25-27.

5. J.W. Dini, W.K. Kelley, W.C. Cowden, and E.M. Lopez: Weld. J., 1984, vol. 63 (1), pp. 26s-34s.

6. J.W. Prybylowski, S. Floreen, W.J. Sherwood, and R.W. Wittmeier: Corrosion, 1991, vol. 47, (3), pp. 210-15.

7. D.S. Duvall, W.A. Owczarski, D.F. Paulonis, and W.H. King: Weld. J., 1972, vol. 51 (2), pp. 41s-49s.

8. G.D. Smith and H.L. Flower: Ind. Heating, 1995, vol. 4, pp. 47-49.

9. G. Humpston and D.M. Jacobson: Principles of Soldering and Brazing, ASM International, Materials Park, OH, 1993, pp. 111-44.

10. D.V. Donford and P.G. Partridge: J. Mater. Sci., 1990, vol. 25 , pp. 4957-64. 